\title{
The Changes of Position and Angulation of Condyle Mandible Before and After Orthodontic Treatment in Class II Malocclusion by Using Cephalometric Radiograph
}

\author{
Nurmuhayannah \\ Department of Orthodontic \\ Faculty of Dentistry, Universitas Sumatera Utara \\ Medan, Indonesia \\ nurmuhayanah@gmail.com
}

\author{
Erna Sulistyawati \\ Department of Orthodontic \\ Faculty of Dentistry, Universitas Sumatera Utara \\ Medan, Indonesia
}

\author{
Nazruddin \\ Department of Orthodontic \\ Faculty of Dentistry, Universitas Sumatera Utara \\ Medan, Indonesia
}

\begin{abstract}
The condyle position is important for the balance of the stomatognathic system. The changes of the condyle position from the normal position can cause Temporomandibular disorders (TMD). Malocclusions may cause condyle position changes at the Temporomandibular joint (TMJ). Treatment of skeletal class II malocclusion is expected to change the position of the condyle into a normal position. The condyle position is measured using two reference lines; Tuberculum sella to Cribiform (TC line) and vertical T line. TC line is formed by tuberculum sella (T) and Cribiform (C); the vertical $T$ line is formed by the line that passing through point $\mathrm{T}$ and is perpendicular to the TC line. The angular measurement of condyle is formed by point Condylion (Co)-T-vertical T line and the position of condyle is formed by Co to TC line and Co to vertical $T$ line. This research is cross sectional design study with analytical statistical approach which compared the position and angular condyle from tracings 36 lateral cephalometric radiograph before and after fixed appliances orthodontic treatment in skeletal Class II malocclusion with maxillary pragmatism. The different condyle position in Co-TC line, Co-vertical T line and angular Co-T-vertical $T$ line shows a significant results $(\mathbf{P}=0.001)$ in skeletal Class II malocclusion with maxillary pragmatism. The distance of the Co to TC line increased, Co to vertical $\mathbf{T}$ line and angular $\mathrm{Co}$ - $\mathrm{T}$-vertical $\mathrm{T}$ line is reduced after fixed appliances treatment in skeletal Class II malocclusion with maxillary pragmatism.
\end{abstract}

Keywords-skeletal Class II malocclusion, maxillary pragmatism, condyle position, TMJ

\section{INTRODUCTION}

Malocclusions are defined as changes in teeth position and skeletal growth which can lead to functional and aesthetic problems. Malocclusions such as crossbite, occlusal interference, crowding, and tooth loss are considered factors for supporting the change of condyle position in temporomandibular joint [1].
Temporomandibular joint (TMJ) is the most complex joint that joins mandible with temporal bone. TMJ consists of condyles, articular discs and glenoidalis fossa. Normally, the articular surface of the condyle is located in the central area (intermediate zone) of the disc. Changes to such positions may cause interference with TMJs or known as Temporomandibular Disorders (TMD) [2,3].

Orthodontists were introduced to the TMD field based on Thompson's theory which states that the malocclusion causes the condyle displacement to the superior (top) and posterior (back). Therefore, there is a need to bring the condyle down and forward by freeing the locked mandible $[2,4]$.

In Class II division 1 skeletal malocclusion, in addition to a large ANB angle from normal, there are six possible complex dentofacial morphologies according to Fisk, among others maxillary and teeth are in a more anterior position in relation to cranium, maxillary proclination teeth with normal maxillary position, normal mandibular size but more posterior position, less developed mandible, retroclination mandibular teeth with normal mandibular position, combination overall [5].

\section{MATERIALS AND METHODS}

The design of this research is cross sectional with paired $\mathrm{T}$ test and Pearson correlation test. The sample consisted of 36 lateral cephalometric radiographs of Class II skeletal with proclination maxillary performed by removal of two maxillary premolars. The patient has finished performing orthodontic treatment. The sample in this study is patient who came from 2007-2017 at RSGMP FKG USU with age range $20-40$ years old. The sample criteria is a class II skeletal patient with a maxillary prognation who has been treated with the 
removal of two maxillary premolars, male and female patients aged 20-40 years old, orthodontic records before and after complete treatment, patients treated with the removal of two maxillary premolars, fixed appliance using standard bracket and Roth slot 0.018 ', cephalometric radiography well and clear, no craniofacial syndrome, no history of trauma around TMJ and chin, no signs and symptoms of TMD. Exclusion criteria include unclear cephalometric radiography, cephalometric radiographic distortion, craniofacial syndrome, history of trauma around the TMJ and chin.

In this study, the position of the condyle (Co) was measured by two reference lines. The ' $\mathrm{X}$ ' axis is formed by the TC line (Cranial base line) and the ' $\mathrm{Y}$ ' axis is formed by a vertical $\mathrm{T}$ line. The TC line is formed by the point $\mathrm{T}$ (tubercullum sella) is the anterosuperior point of the anterior wall of the sella turcica, while $\mathrm{C}$ (cribiform) is the anterior most point of the cribiform plate at the encounter with the nasal bone. The TC line is used as the reference line in this studies because it is a stable line and unchanged after 5 years old. Furthermore, Viazis (2001) reported that the TC line acts as a stable and unchanged cranial reference line with growth. The linear measurements used to determine the position of the condyle on the cranial base are Condylion (Co) to the TC and Condylion (Co) lines to the Vertical $\mathrm{T}$ line (Vert-T). In this study compared any measurements of the sample groups before and after orthodontic treatment as shown in Figure $1[1,6,7]$.

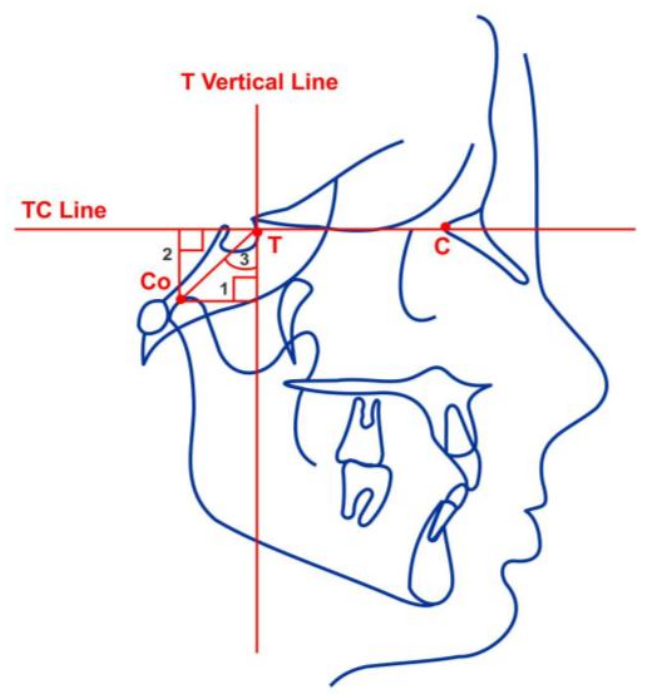

Figure 1. Measurement of position and angulation on the condyle. Note: Co: Condylion, T: Tubercullum sella, C: Cribiform, 1: Co-T vertical, 2: Co-TC, 3: Co-T-T vertical angle $[1,6,7]$.

\section{RESULTS}

To know the distribution of before and after treatment data, Shapiro-Wilk normality test is used because the sample in this research is less than 50. The result shows that the data is normally distributed because of its value $>0.05$ (Table I).
TABLE I. NORMALITY TEST OF KOLMOGORO-SMIRNOV AND SHAPIRO-WILK

\begin{tabular}{|l|c|c|c|c|c|c|}
\hline \multirow{2}{*}{} & \multicolumn{3}{|c|}{$\begin{array}{c}\text { Kolmogorov- } \\
\text { Smirnov }^{\text {a }}\end{array}$} & \multicolumn{3}{c|}{ Shapiro-Wilk } \\
\cline { 2 - 7 } & Statistic & Df & Sig & Statistic & Df & Sig \\
\hline $\begin{array}{l}\text { Co-Tv distance } \\
\text { (before) }\end{array}$ & .074 & 36 & $.200^{*}$ & .986 & 36 & .918 \\
\hline $\begin{array}{l}\text { Co-Tv distance } \\
\text { (after) }\end{array}$ & .064 & 36 & $.200^{*}$ & .984 & 36 & .867 \\
\hline $\begin{array}{l}\text { Co-TC distance } \\
\text { (before) }\end{array}$ & .118 & 36 & $.200^{*}$ & .953 & 36 & .134 \\
\hline $\begin{array}{l}\text { Co-TC distance } \\
\text { (after) }\end{array}$ & .082 & 36 & $.200^{*}$ & .979 & 36 & .723 \\
\hline $\begin{array}{l}\text { Co-T-Tv angle } \\
\text { (before) }\end{array}$ & .067 & 36 & $.200^{*}$ & .976 & 36 & .624 \\
\hline $\begin{array}{l}\text { Co-T-Tv angle } \\
\text { (after) }\end{array}$ & .111 & 36 & $.200^{*}$ & .969 & 36 & .398 \\
\hline
\end{tabular}

The average value distribution \pm standard deviation of the condyle position (Co-T vertical distance and Co$\mathrm{TC}$ distance) and angulation (vertical Co-T-T angle) before and after treatment can be seen in Tables II and III.

TABLE II. DISTRIBUTION OF AVERAGE CO-T VERTICAL, COTC, VERTICAL CO-T-T VERTICAL BEFORE TREATMENT

\begin{tabular}{|l|l|l|}
\hline \multicolumn{1}{|c|}{ Variable } & N & Mean \pm SD \\
\hline Co-T vertical distance & 36 & $21.51 \pm 4.25$ \\
\hline Co-Tc distance & 36 & $21.36 \pm 4.53$ \\
\hline Co-T-T vertical angle & 36 & $45.67 \pm 8.88$ \\
\hline
\end{tabular}

TABLE III. DISTRIBUTION OF MEAN VALUES OF CO-T VERTICAL, CO-TC, CO-T-T VERTICAL ANGLE AFTER TREATMENT

\begin{tabular}{|l|c|c|}
\hline \multicolumn{1}{|c|}{ Variable } & N & Mean \pm SD \\
\hline Co-T vertical distance & 36 & $18.78 \pm 4.04$ \\
\hline Co-Tc distance & 36 & $22.54 \pm 4.48$ \\
\hline Co-T-T vertical angle & 36 & $40.59 \pm 8.47$ \\
\hline
\end{tabular}

Position and condyle angulation before and after treatment were analyzed using SPSS 20.0 program with $\mathrm{T}$ paired test method, significance value $\mathrm{p}<0.005$. The $\mathrm{p}$ value for the vertical Co-T distance, the Co-TC distance and the vertical Co-T-T angle is 0.001. This suggests that there is a significant difference in the position and angulation of the condyle before and after treatment on Class II skeletal malocclusion with the removal of the two maxillary premolars, as shown in Table IV.

TABLE IV. ANALYSIS OF CO-T VERTICAL, CO-TC, CO-T-T VERTICAL ANGLE BEFORE AND AFTER TREATMENT (T-PAIRED)

\begin{tabular}{|l|c|c|c|c|}
\hline \multicolumn{1}{|c|}{ Variable } & $\mathbf{N}$ & $\begin{array}{c}\text { Mean } \pm \text { SD } \\
\text { (before } \\
\text { treatment) }\end{array}$ & $\begin{array}{c}\text { Mean } \pm \text { SD } \\
\text { (after } \\
\text { treatment) }\end{array}$ & $\begin{array}{c}p- \\
\text { value }\end{array}$ \\
\hline $\begin{array}{l}\text { Co-T vertical } \\
\text { distance }\end{array}$ & 36 & $21.51 \pm 4.25$ & $18.78 \pm 4.04$ & $0.001^{*}$ \\
\hline Co-TC distance & 36 & $21.36 \pm 4.53$ & $22.54 \pm 4,48$ & $0.001^{*}$ \\
\hline $\begin{array}{l}\text { Co-T-T vertical } \\
\text { angle }\end{array}$ & 36 & $45.67 \pm 8.88$ & $40.59 \pm 8.47$ & $0.001^{*}$ \\
\hline
\end{tabular}

Data analysis to see the correlation of different variables, namely vertical Co-T distance; Co-TC spacing and Co-T-T vertical angle used Pearson correlation because the data is distributed normally. 
Based on Pearson correlation test, there is a strong positive correlation for Co-TC distance with vertical Co-T-T angle with $\mathrm{r}=0,075$ (table 5). While the correlation between Co-TC distance with Co-T-T vertical angle and Co-TC distance with $\mathrm{C}$-T vertical distance is negative correlation.

\section{DISCUSSION}

TMJ is considered one of the most complex joint in human body and has a strong relationship with dental occlusion and jaw relation. The position and function of the condyle is usually affected by age, facial growth patterns, pathological functional changes, decreased or increased muscle activity, occlusal force, and teeth occlusion [1]. Class II skeletal malocclusion can be treated in several ways based on characteristics according to the patient's condition such as anteroposterior discrepancy, age, cooperative patient. Patients in growth stage, Class II skeletal malocclusion treatment may be performed with growth modification, whereas in adult patients, where growth does not occur again, camouflage treatment with permanent tooth extraction and orthognathic surgery is an option $[8,9]$.

A study by Chaukse et al comparing condyle relation in Class I and II skeletal malocclusion, where the condyle in Class II skeletal case has greater angulation and lies more posteriorly in glenoidalis fossa. Study of Burke et al showed a reduction in vertical depth or superior joint space in a Class II skeletal case that exhibits similarities with bone structure, therefore Class II skeletal case is susceptible to erosion and condyle degradation in the glenoidalis fossa [10].

In this study, changes in the condyle position (Co-T vertical distance and Co-TC distance) and condyle angulation (Co-T-T vertical angle) after treatment were significant with $\mathrm{p}=0.001$. Class II skeletal malocclusion treatment camouflaged by the removal of two maxillary premolars causes inferior condylous repositioning by value of $22.54 \pm 4.48$ and forwards (anteriorly) by value of $18.78 \pm 4.04$ and a reduction of the condyle angle by value $40.59 \pm 8.47$.

Based on table II and III, it can be seen that the vertical Co-T distance after treatment is greater. This shows the position of the condyle in the vertical direction increase inferiorly. The vertical Co-T spacing is shorter after treatment indicates that after treatment the condyle position is closer to the articular eminence. While the Co-T-T vertical angle is also smaller after the treatment shows the posterior position more inferior and anteriorly compared before treatment.

Based on the correlation analysis, there is a positive or direct and strong correlation between the Co-TC distance and the Co-T-T vertical angle that is after the Co-TC distance treatment is greater while the Co-T-T vertical angle is smaller. The correlation analysis only compares two numerical variables. Correlation of $\mathrm{Co}-\mathrm{T}$ vertical distance and Co-T-T vertical angle and Co-TC distance and Co-T vertical distance were negative. The condyle moves to a more inferior position within the glenoidal fossa as a consequence of orthodontic treatment. Although statistical results suggest that the condyle moves anteriorly and inferiorly significantly, this fact may not affect TMJ clinical signs. Occlusion has been recognized as an important factor to cause TMD, however, to date; many scientific studies have shown that orthodontic treatment is not directly related to temporomandibular disorder (TMD) [1].

From the results of this study can be concluded that there is a significant difference in position and angulation of the condyle before and after treatment in Class II skeletal malocclusion with the removal of two maxillary premolars. Next, the position and angulation of the mandibular condyle on Class II skeletal malocclusion is more posterior and has large angulation.

\section{REFERENCES}

[1] J.K. Khoo, T. Bregman, L. Avi, R.N. Firman, "Evaluation of changes in TMJ position for angle Class I malocclusion after orthodontic treatment by using cephalometric radiograph," UIP Health Med., vol. 1(1), pp. 58-62, 2016.

[2] J. Okeson, Management of temporomandibular disorder and occlusion, $7^{\text {th }}$ ed., Kentucky: Elsevier Limited, 2008, pp. 74.

[3] L.A. Ferreira, "Indication criteria of imaging exams for diagnosing of temporomandibular joint disorders," J. Clin. Exp. Pathol., vol. 4(5), pp. 1-6, 2014

[4] A.F. Hegab, "TMJ splint therapy; then what?" J. Dental Health, Oral Disorders \& Therapy, vol. 3(2), pp. 1-2, 2015.

[5] S.E. Bishara, "Class II malocclusions: diagnostic and clinical considerations with and without treatment," Seminar in Orthodontics, vol. 1(12), pp. 11-24, 2006.

[6] A. Mengi, et al., "The glenoid fossa location in cranial base: In various skeletal malocclusions," J. of Dental Herald, vol. 2(2), pp. 6-10, 2015.

[7] A. Mengi, V.P. Sharma, P. Tandon, A. Agarwal, A. Singh, "A cephalometric evaluation of the effect of glenoid fossa location on craniofacial morphology," J. of Oral Biology and Craniofacial Research, vol. 6, pp. 204-212, 2016.

[8] A.F. Hegab, "TMJ splint therapy; then what?" J. Dental Health, Oral Disorders \& Therapy, vol. 3(2), pp. 1-2, 2015.

[9] J.P. Okeson, "Evolution of occlusion and temporomandibular disorder in orthodontics: Past, present, and future," Am. J. Orthod. Dentofac. Orthop., vol. 147, pp. 216-223, 2015.

[10] A. Chaukse, et al., "Computed tomographic analysis of condylefossa relationship in skeletal class I and skeletal class II vertically growing males," Journal of Orthodontic Research, 3(3), pp. 170-174, 2015. 